\title{
The effect of stress on customer perception of the frontline employee: an experimental study
}

\author{
Marie-Christin Papen ${ }^{1}$ - Thomas Niemand ${ }^{2,3} \cdot$ Florian U. Siems $^{1} \cdot$ \\ Sascha Kraus ${ }^{3}$
}

Received: 24 February 2017/ Accepted: 3 November 2017/Published online: 15 November 2017

(C) The Author(s) 2019, corrected publication 2019

\begin{abstract}
This article examines positive effects of customer stress drawn upon the theory of excitation transfer. Contrary to previous marketing and management literature, the present study focuses on positive outcomes of stress based on a study by Dutton and Aron (J Pers Soc Psychol 30(4):510-517, 1974), who found increasing interpersonal attraction in stressful situations in a private context. The present study examines whether these findings can be applied to a service context and how interpersonal liking affects customer's employee perception and customer-related responses. An experimental laboratory study $(N=104)$, including a service-employee interaction and a psychological stress induction (Social Evaluative ColdWater Pressure Test [SECPT]), was conducted. Results indicate a positive effect of stress on relationship quality constructs (relationship trust, commitment, satisfaction, and relationship investment) and partially on behavioral constructs, fully mediated by the customer's interpersonal liking of the service employee. The present research contributes to marketing and management literature in two ways: it highlights (a) the importance of context and emotion for the perception of the employee, and (b) the relevance of interpersonal liking of the service employee for the long-term customer relationship.
\end{abstract}

Marie-Christin Papen

marie-christin.papen@tu-dresden.de

Sascha Kraus

sascha.kraus@gmail.com

1 Department of Marketing, Technical University Dresden, Helmholtzstrasse 10, 01062 Dresden, Germany

2 Clausthal University of Technology, Institute of Management and Economics, Albrecht-vonGroddeck-Strasse 7, 38678 Clausthal-Zellerfeld, Germany

3 University of Liechtenstein, Institute for Entrepreneurship, Fürst-Franz-Josef-Strasse, 9490 Vaduz, Liechtenstein 
Keywords Stress - Relationship quality - Excitation transfer - Interpersonal liking $\cdot$ Service marketing $\cdot$ Employee perception

JEL Classification M31 · M12

\section{Introduction}

The topic of stress is an everyday phenomenon. Almost everyone is familiar with the feeling of being stressed, and this condition is usually perceived as uncomfortable (Crum et al. 2013). However, especially in today's fast-moving society, stress is often inevitable. Medicine and social sciences focus on negative consequences of stress. Stress is viewed, for example, as a major cause of cardiovascular and other diseases (Backé et al. 2012; Cohen et al. 1993). In addition to these serious consequences, stress can even affect everyday decisions in activities such as shopping or eating (Starcke and Brand 2012). Nevertheless, under certain circumstances, stress can lead to positive outcomes (for an overview, see Crum et al. 2013). In marketing research, only a few studies examine the role of stress (Moschis 2007), whereby the majority of studies focus on the emergence of negative consumer habits (e.g., Ruvio et al. 2014; Sneath et al. 2009), biased product or service evaluation (e.g., Maier and Wilken 2014), or contact employee stress (e.g., Chan et al. 2010; Leischnig et al. 2015; Nixon et al. 2011). Hence, marketing research also focuses on negative consequences of stress. So far, positive outcomes have not been investigated. In a positive way, stress can generally lead to improved focus on the actual task, and employees can enhance skills to complete a task in stressful situations (Crum et al. 2013; Fay and Sonnentag 2002). Besides these positive consequences for tasks, stress can also positively affect the evaluation of other people (Dutton and Aron 1974; Foster et al. 1998). Accordingly, the question arises whether existing insights of positive effects of stress can be transferred to marketing, especially to service interactions, by taking the perspective of stress as a state of arousal (e.g., Maier and Wilken 2014) that is connected to increased attention and increased heart rate.

Most prominently, Dutton and Aron (1974) examined the influence of arousal on interpersonal attraction in a private context. They found that arousal can result in increasing interpersonal attraction. This link can be explained by the theory of excitation transfer specified by Zillmann (1971). The theory describes a shift of the attribution of excitement, resulting from two different stimuli to only one. For example, showing pictures of attractive people in stressful situations can improve the perceived attractiveness of the pictured people. A general link between arousal and interpersonal attraction was found by Clore and Gormly (1974). The existing relationship between arousal and liking in a personal context begs the question of whether it can also be found in a professional context, for example, increased interpersonal liking (IPL) between customer and contact employee. In industries with intense contact between employees and customers, especially service industries, personal sympathy and IPL play a vital role and can reinforce outcomes 
such as trust in a customer context (Albrecht et al. 2016; Darden et al. 1991; Nicholson et al. 2001).

In terms of long-term relationships between companies and customers, relationship quality, in which trust is one facet, is essential (Tang et al. 2017). As described by Palmatier et al. (2006), efforts in relationship marketing can lead to stronger customer relationships, and in a second step, to increasing performance of a company. Together with the results of Nicholson et al. (2001), it can be assumed that IPL also positively affects other components of relationship quality. As previously described, stress is an everyday phenomenon, even in the context of product and service evaluation. A consideration of the positive effects of customer stress on service employee perception, and in turn, on long-term customer-company relationships, therefore appears insightful. Having knowledge about the positive effects of stress on IPL and its outcomes enables marketers and managers to actively design and/or manage situations in which the activating and motivating excitement improves relationships between customers and the company. Similar to most branches, services are subject to massive and fast-moving changes. Therefore, besides the approach of relationship marketing, the perspective of entrepreneurial marketing (EM) also seems relevant. In this context, EM integrates marketing and entrepreneurship perspectives to search for novel approaches to acquire and retain customer groups (Morris et al. 2002; Kraus et al. 2012). With respect to EM, the present paper particularly contributes to the customer focus central in EM by highlighting the positive effect of stress to deepen the firm-customer relationship as well as value creation by showing how innovative values can be built (or destroyed) in stressful situations.

The purpose of the present paper is twofold: On the one hand, a positive effect of customer stress on IPL in a service setting is investigated for the first time in a marketing context; on the other hand, it is explored how this customer perception (represented by IPL) can, in turn, affect perceived relationship quality, relationship investment, and thus behavioral intentions, such as word-of-mouth intention (WoM) and repurchase intention. To the best of the authors' knowledge, the positive effects of stress have not previously been examined in this context. In the context of EM the present paper seeks to contribute to existing literature by adding experimental research that could also be integrated into an EM perspective. According to Wales et al. (2013), there is a lack of experimental studies in entrepreneurial research. To close the void of possible positive effects in marketing, and aiming toward high external and internal validity, a complex experiment, including an interaction between customer and employee in a service setting and a psychological stress induction, was conducted.

\section{Theoretical background and hypotheses}

\subsection{Previous research on stress}

Stress is given an important role in sociology and psychology research (Bodenmann et al. 2010; Slavich and Irwin 2014). In this context, stress can be defined as a "state 
of imbalance within a person, elicited by an actual or perceived disparity between environmental demands and the person's capacity to cope with these demands" (Maes et al. 1987, p. 567). This definition illustrates the subjective character of stress, since it can also result from a perceived gap between demands and individual ability (Maier and Wilken 2014, p. 775). It can be viewed as a response (e.g., behaving nervously), a stimulus (a stressor), or a combination of both (Lazarus and Folkmann 1984; Ruvio et al. 2014). According to Moschis (2007), integrating stress as a response is becoming more popular in research compared to viewing it solely as a stimulus, because it is based on a subjective assessment and is therefore more useful. This position is in line with the definition of Maes et al. (1987), since the individual's perception is in the foreground. Following Lazarus and Folkmann (1984), in the present paper a combination of both perspectives of stress is integrated: a stimulus (in the present experiment, a concrete stressor was presented) as well as a response (participant's reaction). According to Maier and Wilken (2014), stress coincides with higher levels of arousal. In addition to the valence, the reference may vary in this context: Stress can affect the ability to make decisions (Kahn and Baron 1995; Kunreuther et al. 2002; Starcke and Brand 2012) or interpersonal relationships (Bodenmann et al. 2010). Intuitively, almost all areas of life can be affected by the presence of stress.

In marketing, there are few studies that examine the role of stress (Moschis 2007). This literature can be grouped into three streams of literature. A first stream focuses on customer stress and the emergence of negative behavior in terms of buying behavior. Sneath et al. (2009) studied the influence of stress caused by a single natural disaster (hurricane Katrina) on purchasing behavior, establishing a link between event-induced stress and depression that can lead to impulsive and compulsive consumption behaviors. Ruvio et al. (2014) examined a thematically close topic: war-related events. The authors applied cross-national field experiments and found effects of post-traumatic, war-induced stress of consumers and maladaptive consumption habits, with a moderation effect of the extent of the subject's materialistic attitude. A highly materialistic attitude is thus associated with higher post-traumatic stress.

A second stream of literature investigates the effect of stress on product or service evaluation. In a conceptual article, Samson and Voyer (2014) considered the impact on purchasing decisions by emergency purchase decisions (EPS) and concluded that urgency (in time and needs) leads to stress among consumers, and the resulting stress affects, in turn, the manner of product evaluation. High levels of stress lead to a more heuristic evaluation compared to a reflective evaluation, with the latter being more careful and relying on costs and benefits of the product. In several studies, Maier and Wilken (2014) examined the effect of stress on customers' willingness to pay for an evaluated product. Stressed customers are willing to pay less for the product, while construal level, as a higher level of abstraction, moderates this effect. Singh and Duque (2012) examined sector-specific aspects in service perception and found that for negative services (e.g., police services), in the case of highly stressed customers, the reduction of stress is more important for a positive service evaluation than fast service delivery. Finally, Etkin 
et al. (2015) showed that stress strengthens the influence of perceived goal conflict on perceived time pressure.

In addition, a growing body of research investigates employee stress in work-lifebalance. Topics include employee stress ("role stress"; Nixon et al. 2011; Wegge et al. 2007) and how employees' stress affects their behavior toward the customer, as well as how this consequently affects customer perception of service and behavioral intentions (Boles and Babin 1996; Netemeyer et al. 2005).

To sum up previous marketing research, only negative consequences of stress have been investigated so far. How stress can be influential for marketing in a positive way, as identified in other fields of research (Crum et al. 2013; Dutton and Aron 1974), is unknown. As demonstrated by these authors, stress can also result in positive outcomes, for instance, in case of a "stress is enhancing" mindset (Crum et al. 2013, p. 717).

As described above, stress results from a deviation between requirements and one's own ability to cope with these requirements. Therefore, it is assumed that high induced stress leads to increased feelings of stress and related reactions.

H1: Participants in the stress group show a higher stress level compared to participants in the control group.

\subsection{Theory of excitation transfer and interpersonal liking}

The theory of excitation transfer was proposed by Zillmann (1971). In general, it refers to a process of misattribution of two different stimuli. A first stimulus reinforces the second one, but the perceived overall result of both stimuli is attributed solely to the second stimulus (Zillmann 1971; Zillmann et al. 1972). To verify the theory, Zillmann (1971) used physical exertion as the first stimulus and aggressive behavior as the second stimulus. According to the author, it is intuitive to assume that the exposure of aggressive communication leads to more aggressive behavior-as stated in previous studies-but the causal relationship was not distinct. He concluded that from a set of possibly underlying variables, excitation is an explanation for the effect. The explanation for the transfer to perception of the second stimulus is closely linked to Schachter's two-factor theory (Schachter 1964; Schachter and Singer 1962). The theory states that emotions (e.g., fear) can be understood as a function of a stimulus with physiological arousal as well as a contextual matching cognition (Schachter 1964). In other words, an emotion arises when a causal attribution of the experience occurs subsequently to the physical stimulus. To illustrate the process, the experimental procedure of the study by Schachter and Singer (1962) is described. Subjects were injected with adrenaline and separated into two groups. One group was informed about the active ingredient being adrenaline, while no information was given to the other group. In the second part of the experiment, subjects from both groups were provoked by a third person in an aggressive way. As a result, the uninformed subjects reported being angry, while the informed subjects attributed their physical excitation to the adrenaline injection and reported not being angry. Thus, the uninformed subjects had only one possible cause (aggressive person) to which they could ascribe their physical 
reaction. Accordingly, the transfer only occurs when the individual is not aware of the first source of excitation (Cantor et al. 1975). Closely linked to the attribution to the second stimulus, the theory of excitation transfer states that excitation from the first stimulus decreases relatively slowly (Cantor et al. 1975). Zillmann and colleagues examined excitation transfer, for instance, in the contexts of aggression (Zillmann 1971; Zillmann et al. 1974) and sexual arousal (Cantor et al. 1975).

Excitation transfer has been examined in marketing literature, especially in the field of TV advertising planning and management. Investigating the influence of commercials framed by film scenes (Mattes and Cantor 1982; Pechmann and Shih 1999), excitement caused by a film scene directly influences the perception of an advertising spot. However, Perry et al. (1997) examined the effects in an opposite direction: exciting or humorous commercials enhanced program enjoyment (Perry 2001). Further, aspects such as the time between viewing a scene and viewing a commercial (Mattes and Cantor 1982) have also been investigated.

Dutton and Aron (1974) examined the theory on a link between high excitement or fear and sexual interpersonal attraction. In their first field study, an attractive female interviewer contacted male subjects close to an existing rope bridge over the Capilano Canyon in Canada (fear treatment) or close to a safe bridge (non-fear treatment). Respondents were asked to complete a questionnaire and write a short story based on a picture of a young woman. The authors found significant differences in written sexual content and post-experimental contact behavior towards the female interviewer between the two groups. Put simply, male participants were more interested in contacting and dating the attractive female interviewer in the context of the fear-arousing bridge. In the excitation context, the participants used more expressions related to love or sex in their short stories than their counterparts close to the safe bridge. In line with excitation transfer theory, the first stimulus (fear-arousing bridge) was transferred to the second stimulus (perception of the experimenter), thus leading to an overestimation of interpersonal attraction. The authors confirmed these results in various other field and laboratory settings. Excitation leads to a more positive assessment, although the reason for the excitation (e.g., an impending potentially painful experiment; study 3) can also be classified negatively (Dutton and Aron 1974).

Increased interest in another person through an arousal-inducing situation in the study by Dutton and Aron (1974) suggests that excitation transfer could affect the perception of contact situations where attraction is more general and not limited to personal (e.g., sexual) attraction. In their experiment, Clore and Gormly (1974) found support for a correlation of arousal and general interpersonal attraction. In their laboratory experiment, participants rated (same sex) strangers in an arousing situation. Similar results for a positive effect of arousal on interpersonal linking were found in a study by Foster et al. (1998), who applied a meta-analytic approach. The authors examined the effect of arousal in romantic and non-romantic contexts. As a result, arousal affects romantic attraction more intensively; however, support for increasing nonromantic attraction was also found. Therefore, it is conceivable that the process could influence not only interactions in a private context but also contact between employees and customers. In this case, the desired outcome variable is not sexual attraction, but sympathy or IPL, which is related to positive 
outcomes (Caballero and Resnik 1986) like trust in the company (Nicholson et al. 2001). The authors describe IPL as “....an emotional connection that one feels for another, that can be viewed as fondness or affection-a feeling that goes beyond the mere acceptance of a competent business partner" and the desire to "be around" this person. IPL leads to personal attachment and increasing economic bonds (Nicholson et al. 2001). Transferred to a business context, the results of the study by Dutton and Aron (1974) imply that a highly excited customer shows higher levels of IPL for the employee than a relaxed customer. Thus, the second hypothesis can be defined as follows:

H2: Stress level has a positive influence on IPL of the service employee.

\subsection{Relationship quality and behavioral intentions}

In the service industry, the contact between customer and employee is vital. Customer's overall service evaluation is strongly influenced by the perception of the interaction with the service employee (Homburg and Giering 2001). The importance of personal interaction in services, in relation to its importance in products, particularly results from service-inherent properties such as intangibility and simultaneity of production and consumption (Mang et al. 2012; Zeithaml et al. 1985). In this context, personal sympathy and IPL are fundamental factors for the emergence of trust (Nicholson et al. 2001; Swan et al. 1985).

In general, long-term relationships between companies (e.g., represented by an employee) and customers are the focus of relationship marketing (Morgan and Hunt 1994; Palmatier et al. 2006). Agariya and Singh (2011) conclude their review of definitions for relationship marketing as "the core of all definitions revolves around acquisition, retention, profitability enhancement, a long-term orientation, and a winwin situation for all stakeholders of the organization" (p. 228). The core instrument for measuring quality and long-term stability of relationships between a customer and a company is relationship quality (Crosby et al. 1990; DeWulf et al. 2001). Following DeWulf et al. (2001), relationship quality can be defined as a higherorder construct containing relationship satisfaction, relationship trust, and relationship commitment. According to the authors, relationship satisfaction can be viewed as a customer's emotional state as a result of interactions with the company (DeWulf et al. 2001; Morgan and Hunt 1994). Relationship trust is described as the belief of the customer in the reliability of the company. The third constructrelationship commitment-includes a customer's eagerness for a continuing relationship and willingness to engage in a relationship (DeWulf et al. 2001). In this context, the authors also refer to relationship investment, described as the perceived effort of the company to build and maintain the relationship with the customer. Nicholson et al. (2001) substantiate the link between IPL and trust with the "fact that more favorable motives are assigned to liked people, an action that builds trust" (p. 5). Based on their findings regarding the impact of IPL on trust, it can be assumed that IPL also affects other relationship quality constructs. This leads to the following hypotheses: 
H3: IPL has a positive influence on perceived relationship quality constructs and perceived relationship investment;

H3a: Relationship satisfaction;

H3b: Relationship trust;

H3c: Relationship commitment;

H3d: Relationship investment.

In addition to the constructs of perceived relationship quality and relationship investment, other indicators to measure the outcome of long-term relationships can be used. According to Palmatier et al. (2006), long-term customers tend to engage in positive WoM, whereby the term WoM is defined as the "likelihood of a customer positively referring the seller to another potential customer" (Palmatier et al. 2006, p. 139). Hence, WoM can capture the external-referral to relevant othersconsequence of a relationship. In short, customers who perceive a relationship with a company as close will likely tell others about their relationship and experience (Grégoire and Fisher 2006). Repurchase intention, in contrast, is often criticized as a single indicator for loyalty (Maxham and Netemeyer 2002) but allows to capture an internal-the consumer decides for oneself-consequence based on the simple argument that highly qualitative relationships will likely promote repeated interactions as a function of security and mutuality (Grönroos 1990). Therefore, repurchase intention in hypothesis $4 \mathrm{~b}$ is regarded as a supplement to WoM intention. Overall, the following hypotheses arise:

H4: Relationship quality constructs and relationship investment have a positive influence on behavioral intention constructs;

H4a-d: WoM intention;

H4e-h: Repurchase intention.

It has to be stressed that based on these hypotheses a 'chain of effects' is expected. Figure 1 illustrates the arrangement of hypotheses as well as the roles that experimental manipulation and constructs take in that chain.

\section{Empirical study}

\subsection{Experimental design}

To test the hypotheses, an empirical study was conducted in a medium-sized city in eastern Germany. The experiment was designed as a one-factor (stress/no-stress), between-subject study in a laboratory setting (Kraus et al. 2016). First, each participant entered an experimental room containing a desk, chair, camera, and a bowl of water. After being welcomed by the female experimenter, the participant was told that the study deals with "relationship marketing." No further information 


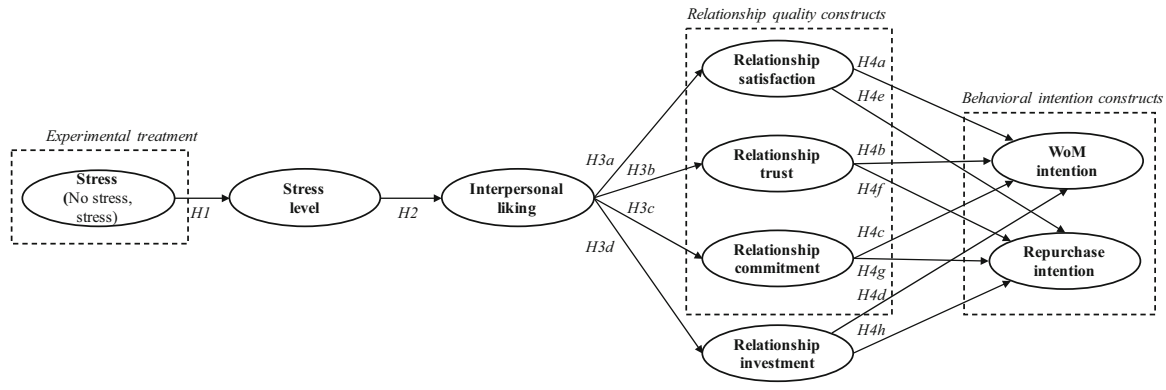

Fig. 1 Chain of effects (Hypotheses) Notes: All hypotheses assume a positive relationship

was provided. After the briefing, participants in the stress condition were treated according to the Social Evaluative Cold-Water Pressure Test (SECPT), as described by Schwabe et al. (2008). Although this is a laboratory method of stress-induction, it triggers comparable physical reactions similar to real-life stress situations (Cheng 2001). The SECPT is well-established in psychological stress research; it combines social and psychological elements of the Trierer Stress Test (TSST; Kirschbaum et al. 1993) and physical elements of the Cold-Water Pressure Test (CPT; Velasco et al. 1997) for stress induction. Consequently, the SECPT includes physical (cold water) and social (being watched and analyzed) stressors. Thus, the method is applicable for participants who respond to social and psychological stimuli, as well as for those participants who do not respond to psychological stimuli but do respond to physical stress-induction. According to the procedure, the participant was asked to immerse one hand in cold water $\left(1-4^{\circ} \mathrm{C}\right)$ for either $3 \mathrm{~min}$ or for as long as possible. At the same time, the female experimenter observed the participant and made notes, including objective stress criteria (e.g., eyelid movement, tremor). She also completed the same stress measure (Tansik and Routhieaux 1999) that the participant was provided subsequently, but with an altered wording to capture the experimenter's perception of the participant's stress level (see Table 2). Meanwhile, the camera recorded the respondents after being told that three male communication researchers would analyze their facial expressions subsequent to the experiment. In contrast to Schwabe et al. (2008), where only male respondents were investigated, the present experiment included both genders to gain more generalizability. According to Schwabe et al. (2008), being observed by a person of the opposite sex contributes to an increasing stress level. To account for the variation described above, all participants were told that the mentioned communication researchers were all male. Hence, this ensured that all participants thought they were being observed by at least one person of the opposite sex (female experimenter; male communication researcher). In the no-stress condition, respondents immersed their hands in warm water $\left(33-38{ }^{\circ} \mathrm{C}\right)$ with no observation by the experimenter (although she was passively present) or camera recording.

In the second part of the experiment, participants were told to test service employees of a hotel-booking hotline. They were instructed to call a booking hotline and obtain a tentative offer for two separate hotel rooms (for themselves and a 
superior) near the fairground of another medium-sized city in eastern Germany. To ensure sufficient interaction time to accurately assess the hotline employee (at least 1:30 min), this task included asking for a vegan breakfast. Participants were provided with fictional names (male and female) and email addresses to be used in the task.

The fictional booking hotline was staffed by a male call-center professional who was instructed to act consistently polite and to recommend the same two (fictional) hotels, including prices and distances from the fairground. This call-center professional was not aware of the treatment group the participant was assigned to. After the telephone conversation the call-center professional filled out the same stress scale (Tansik and Routhieaux 1999) as the participants and female experimenter based on his impression of the participant's voice to gain a more extensive evaluation of the participant's stress level.

After having finished the call, participants were asked to fill out a paper-based questionnaire. The seven-point Likert scales for IPL (Nicholson et al. 2001) were slightly modified to fit the case of employee contact via telephone. In addition to the item from the original scale, "I like this service employee as much as other people I know," we supplemented "I like this service employee more than other people I know," and "I like this service employee less than other people I know." The modification was necessary to better assess the assumed direction (positive or negative) in case of a low agreement. The questionnaire also included repurchase intention (three items; Maxham and Netemeyer 2002), WoM intention (four items; Zeithaml et al. 1996), and a stress measurement (three items; Tansik and Routhieaux 1999). Participants were asked how they thought the booking company would behave toward regular customers based on the constructs of perceived relationship quality and perceived relationship investment (trust, three items; commitment, three items; satisfaction, three items; and investment, three items; all four adapted from DeWulf et al. 2001). The questionnaire ended with demographics and several questions related to personal aspects. In this section, participants were also asked if they smoke and how many cigarettes they smoke daily. According to Kirschbaum et al. (1993), nicotine consumption affects participants' responsiveness to stress. All multi-item scales used seven-point Likert-type scale formats and were translated into German and verified by back translation. Item wordings are provided in Tables 1 and 2. After completion of the experiment, participants were debriefed via email.

\subsection{Sample structure}

The sample included 104 participants (55\% male) with a mean age of 29.73 (range: 20-64 years). Sixty-three percent were students, and the other participants were employees or workers $(20 \%)$, freelancers $(7 \%)$, job seekers $(5 \%)$, or others $(5 \%)$. Two participants were excluded due to an incomplete questionnaire and calling task. Participants were recruited by attendees of a seminal course as part of the universities' master's programs. As an incentive, all participants were given the opportunity to participate in a lottery for three Amazon vouchers (30 euros each). To prevent any physical harm, people with cardiovascular diseases were excluded in 
Table 1 Loadings for relationship quality an interpersonal liking

\begin{tabular}{|c|c|c|}
\hline Measure & Item & Loading \\
\hline \multirow{5}{*}{$\begin{array}{l}\text { Interpersonal liking } \\
\text { (IPL) }\end{array}$} & Even without our business ties, I would choose to talk to the employee & .51 \\
\hline & I like the employee more than other people that I know & 65 \\
\hline & I like the employee less than other people that I know & .47 \\
\hline & I like the employee as much as other people that I know & .59 \\
\hline & I enjoy to talk to the employee & .59 \\
\hline \multirow[t]{3}{*}{$\begin{array}{l}\text { Relationship } \\
\text { satisfaction }\end{array}$} & $\begin{array}{l}\text { As a regular customer, I have a high-quality relationship with this } \\
\text { supplier }\end{array}$ & .85 \\
\hline & $\begin{array}{l}\text { I am happy with the efforts this supplier is making toward regular } \\
\text { customers like me }\end{array}$ & .83 \\
\hline & I am satisfied with the relationship I have with this supplier & .69 \\
\hline \multirow[t]{3}{*}{ Relationship trust } & This supplier gives me a feeling of trust & .82 \\
\hline & I have trust in this supplier & .90 \\
\hline & This supplier gives me a trustworthy impression & .73 \\
\hline \multirow[t]{3}{*}{$\begin{array}{l}\text { Relationship } \\
\text { commitment }\end{array}$} & $\begin{array}{l}\text { I am willing "to go the extra mile" to remain a customer of this } \\
\text { supplier }\end{array}$ & .79 \\
\hline & I feel loyal toward this supplier & 60 \\
\hline & $\begin{array}{l}\text { Even if this supplier would be more difficult to reach, I would still keep } \\
\text { using the service }\end{array}$ & .74 \\
\hline \multirow{3}{*}{$\begin{array}{r}\text { Relationship } \\
\text { investment }\end{array}$} & This supplier makes efforts to increase regular customers' loyalty & .78 \\
\hline & $\begin{array}{l}\text { This supplier makes various efforts to improve its ties with regular } \\
\text { customers }\end{array}$ & .73 \\
\hline & This supplier really cares about keeping regular customers & .89 \\
\hline
\end{tabular}

Loadings $=$ standardized loading from CFA on single factor of measure

advance (Schwabe et al. 2008). Participants were randomly assigned to one of the two groups. Overall, 52 participants were assigned to the no stress treatment, and 50 to the stress treatment.

\subsection{Analysis and results}

\subsubsection{Overview of approaches}

The analysis is structured as follows: first, conditions for analysis of individual hypotheses were tested. For all multi-item variables, indices were used to represent the underlying construct. All constructs exceeded the minimum requirements (.7) of reliability in terms of Cronbach's $\alpha$ (Table 3), dimensionality checks in explorative factor analysis (EFA), and convergent validity (confirmatory factor analysis, CFA, with average variance extracted, AVE, $>.5$, Table 3 ). To verify discriminant validity, the Fornell-Larcker criterion (Fornell and Larcker 1981) was applied. All multi-item constructs were found to be discriminant, as average variance extracted was constantly larger than squared correlations with all other constructs. The stress 
Table 2 Loadings for behavioral intentions and stress

\begin{tabular}{llc}
\hline Measure & Item & Loading \\
\hline $\begin{array}{l}\text { Repurchase } \\
\text { intention }\end{array}$ & In the future, I intend to use services from Hoteldirekt & .67 \\
& In the near future, I will not use Hoteldirekt as my provider (reverse) & .69 \\
& If you were in the market for hotel-booking service, how likely would you & .74 \\
bord-of-mouth & I am likely to say positive things about this hotel-booking hotline to other & .89 \\
intention & people & .94 \\
& I am likely to recommend this hotel-booking hotline to a friend or & .88 \\
& colleague & .80 \\
& I am likely to say positive things about the hotel-booking hotline in & .47 \\
& general to other people & .88 \\
I am likely to encourage friends and relatives to use the service of the & .83
\end{tabular}

Loadings = standardized loading from CFA on single factor of measure. Stress loadings derived from separate factors for self-, employee-, and experimenter-assessment

level measure consisted of three different dimensions (self-reports from participant, experimenter, and "employees" scoring) to account for: (a) social desirability biases, because participants may state that they were not nervous or anxious, contradictory to their apparent behavior (e.g., red face, tremor, rapid eyelid movement); and (b) experimenter biases in evaluation of stress level, possibly caused by condition knowledge (stress or no stress).

Second, having established the validity of our constructs, we applied two approaches to address the multi-stage nature of our chain of effects to test the hypotheses. Following Bagozzi and Yi (1989), we used a SEM-based multi-stage model with treatment groups being a dummy variable $(0=$ no stress group, $1=$ stress group). Further, we applied multiple mediation models following Preacher and Hayes (2008) that model all proposed mediations: (a) treatment $\rightarrow$ stress level $\rightarrow$ IPL; (b) stress level $\rightarrow$ IPL $\rightarrow$ relationship quality/ relationship investment; and (c) IPL $\rightarrow$ relationship quality/relationship investment $\rightarrow$ behavioral intention variables. Again, stress was used as a dummy variable with identical coding. 
Table 3 Correlations and reliability of constructs

\begin{tabular}{|c|c|c|c|c|c|c|c|c|}
\hline & ST & IPL & RI & RS & RT & $\mathrm{RC}$ & WoM & $\mathrm{RP}$ \\
\hline ST & .73 & & & & & & & \\
\hline IPL & .23 & .70 & & & & & & \\
\hline RI & -.07 & .22 & .85 & & & & & \\
\hline RS & -.15 & .17 & .71 & .83 & & & & \\
\hline RT & -.17 & .22 & .51 & .65 & .85 & & & \\
\hline $\mathrm{RC}$ & -.01 & .32 & .34 & .41 & .47 & .74 & & \\
\hline WoM & -.03 & .36 & .47 & .46 & .44 & .24 & .92 & \\
\hline $\mathrm{RP}$ & -.07 & .26 & .52 & .48 & .36 & .24 & .68 & .74 \\
\hline$M$ (stress) & 3.53 & 4.14 & 5.22 & 5.27 & 5.61 & 3.59 & 5.02 & 5.08 \\
\hline$S D$ (stress) & .64 & .94 & .97 & .86 & .77 & 1.21 & 1.26 & 1.18 \\
\hline$M$ (no stress) & 3.21 & 4.16 & 5.03 & 5.23 & 5.67 & 4.01 & 5.27 & 5.13 \\
\hline$S D$ (no stress) & .82 & 1.04 & 1.19 & 1.16 & .95 & 1.20 & 1.25 & 1.15 \\
\hline
\end{tabular}

Diagonal elements Cronbach's $\alpha$ (italic)

$S T$ stress level, $I P L$ interpersonal liking, $R I$ relationship investment, $R S$ relationship satisfaction, $R T$ relationship trust, $R C$ relationship commitment, $W o M$ word-of-mouth intention, $R P$ repurchase intention, $M$ Mean, $S D$ Standard deviation

\subsubsection{SEM-approach to the chain of effects}

With this approach, we investigated whether the chain of effects by the proposed hypotheses holds together. To do so, a dummy variable for the treatment as well as index scores for the continuously measured variables were applied within a covariance-based structural equation model to obtain estimates via Maximum Likelihood (Bagozzi and Yi 1989). Our models were set up with all variables from a previous stage being considered as predictors. For example, relationship satisfaction was modeled to be influenced from stress treatment, stress level, and IPL. Figure 2 depicts the results. With respect to the dummy stress treatment variable, it should be noted that the unstandardized path coefficient to stress level $(b=.318$,

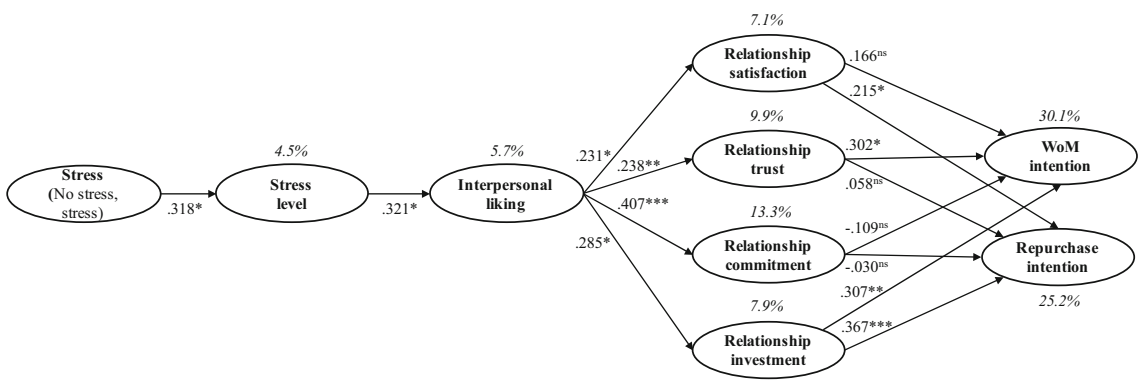

Fig. 2 Chain of effects (SEM-based model results). Notes: Unstandardized estimates, $* p<.05$, $* * p<.01, * * * p<.001$, ns: $p>.05$; Italic values are partial $\mathrm{r}$-squares for dependent variables 
$t(101)=2.205, p<.05)$ estimated the overall difference in stress level between both groups $\left(M_{\text {no stress }}=3.21, S D=.820 ; M_{\text {stress }}=3.53, S D=.637\right)$ equal to a $t$ test or one-factor ANOVA. Stress level itself promoted IPL $(b=.321$, $t(101)=2.236, p<.05)$, supporting H1. In turn, IPL increased relationship satisfaction $(b=.231, t(101)=1.998, p<.05)$, relationship trust $(b=.238$, $t(101)=3.172, p<.01)$, relationship commitment $(b=.407, t(101)=3.723$, $p<.001)$, and relationship investment $(b=.285, t(101)=2.532, p<.05)$. Thus, hypothesis H3a-d were confirmed. Further, IPL influenced WoM intention $(b=.330, t(101)=2.124, p<.01)$ but not repurchase intention $(b=.185$, $t(101)=1.474, p>.05)$. As a consequence, relationship satisfaction $(b=.166$, $t(101)=1.417, \quad p>.05) \quad$ and relationship commitment $(b=-.109$, $t(101)=1.278, p>.05)$ had no effect, while relationship trust $(b=.302$, $t(101)=2.333, p<.05)$ and relationship investment $(b=.307, t(101)=2.998$, $p<.01$ ) had an effect on WoM intention, confirming H4b and H4d, but rejecting $\mathrm{H} 4 \mathrm{a}$ and H4c. Likewise, relationship satisfaction $(b=.215, t(101)=2.139$, $p<.05)$ and relationship investment $(b=.367, t(101)=3.924, p<.001)$ influenced repurchase intention, but neither relationship trust $(b=.058, t(101)=.524$, $p>.05)$ nor relationship commitment did $(b=-.030, t(101)=.299, p>.05)$. Hence, $\mathrm{H} 4 \mathrm{e}$ and $\mathrm{H} 4 \mathrm{~h}$ were confirmed, but not $\mathrm{H} 4 \mathrm{f}$ or $\mathrm{H} 4 \mathrm{~g}$. In an exploratory lens, IPL explained between $7.1 \%$ for relationship satisfaction and $30.1 \%$ for WoM intention of variance in those outcomes. The stress manipulation revealed a power of .703 ( $p=.05$, one-sided). Relationship investment on repurchase intention (power $=.988$ ) revealed the largest power; IPL effect on relationship satisfaction (power $=.742)$ displayed the lowest power among significant hypotheses $(p<.05)$.

\subsubsection{Linear regressions for mediations}

Next, we turn to the second approach and tested whether the proposed mediations were present. Again, a dummy variable was used to capture the stress treatment groups. In line with Preacher and Hayes (2008), a bootstrapping approach (5000 resamples) was used to obtain the indirect effect standard errors and significance tests ( $t$-test) as well as 95\% confidence intervals (termed LCI and UCI for lower and upper confidence intervals). Again, predictors from a previous stage were also modeled. It is noted that the indirect effects are calculated post hoc and not used for hypothesis testing.

Regarding hypothesis $\mathrm{H} 2$ that states that a higher stress level is connected to increasing IPL for the service employee, stress treatment significantly increased stress level $(b=.318, t(101)=2.183, p<.05)$, and stress level in turn raised IPL $(b=.321, t(101)=2.444, p<.05)$ confirming H1. The indirect effect indicated a significant mediation (indirect effect $=.102, p<.05, \mathrm{LCI}=.002, \mathrm{UCI}=.250$ ).

In line with Nicholson et al. (2001), a positive effect of IPL on (perceived) relationship quality constructs and relationship investment was expected. For relationship satisfaction, IPL promoted relationship satisfaction $(b=.231$, $t(101)=2.228, p<.05)$ and by that way mediated stress level effects (indirect effect $=.073, p<.05, \mathrm{LCI}=.002, \mathrm{UCI}=.181)$. This mediation was also found for relationship trust $(b=.238, t(101)=2.758, p<.01$, indirect effect $=.076$, 
$p<.05, \quad \mathrm{LCI}=.001, \quad \mathrm{UCI}=.176), \quad$ relationship $\quad$ commitment $\quad(b=.407$, $t(101)=3.399, \quad p<.001, \quad$ indirect $\quad$ effect $=.133, \quad p<.05, \quad$ LCI $=.020$, $\mathrm{UCI}=.282)$, and relationship investment $(b=.285, t(101)=2.588, p<.05$, indirect effect $=.092, p<.05, \mathrm{LCI}=.006, \mathrm{UCI}=.218$ ). Thus, hypotheses H3a, $\mathrm{H} 3 \mathrm{~b}, \mathrm{H} 3 \mathrm{c}$, and $\mathrm{H} 3 \mathrm{~d}$ are confirmed. Results showed that perceived relationship investment was, as expected, positively affected by IPL. That is, personal sympathy increases the likelihood that a customer evaluates a company to be caring and active. Likewise, relationship commitment defined as "a willingness to maintain a relationship with a firm" (Grégoire et al. 2009, p. 20) was also positively affected by IPL.

Further, it was assumed that relationship quality and relationship investment increased behavioral intention constructs. However, with respect to the dependent variable WoM intention, this hypotheses could only be confirmed for relationship investment $(b=.307, t(101)=2.222, p<.05$, indirect effect $=.087, p<.05$, $\mathrm{LCI}=.005, \mathrm{UCI}=.213)$, but not for relationship satisfaction $(b=.166$, $t(101)=1.000, \quad p>.05, \quad$ indirect $\quad$ effect $=.038, \quad p>.05, \quad$ LCI $=-.039$, $\mathrm{UCI}=.149)$, relationship trust $(b=.302, t(101)=1.799, p>.05$, indirect effect $=.072, p>.05, \mathrm{LCI}=-.004, \mathrm{UCI}=.188)$, and relationship commitment $(b=-.109, \quad \mathrm{t}(101)=1.060, \quad p>.05, \quad$ indirect $\quad$ effect $=-.044, \quad p>.05$, $\mathrm{LCI}=-.147$, UCI $=.040)$. Hence, only $\mathrm{H} 4 \mathrm{~d}$ could be confirmed; $\mathrm{H} 4 \mathrm{a}-\mathrm{c}$ were rejected. Instead, IPL directly influenced satisfaction, trust, and commitment.

For repurchase intention, the same pattern was found. Relationship investment $(b=.367, t(101)=2.794, p<.01$, indirect effect $=.104, p<.05$, LCI $=.014$, $\mathrm{UCI}=.236)$ but not relationship satisfaction $(b=.215, t(101)=1.365, p>.05$, indirect effect $=.038, p>.05, \mathrm{LCI}=-.039, \mathrm{UCI}=.149)$, relationship trust $(b=.058, t(101)=.362, p>.05$, indirect effect $=.014, p>.05$, LCI $=-.067$, $\mathrm{UCI}=.098)$, and relationship commitment $(b=-.030, t(101)=.307, p>.05$, indirect effect $=-.012, p>.05, \mathrm{LCI}=-.098, \mathrm{UCI}=.070)$ significantly mediated IPL on repurchase intention (Table 4). Consequentially, H4e was confirmed, but not $\mathrm{H} 4 \mathrm{f}-\mathrm{h}$. In an explorative manner, IPL did not directly influence satisfaction, trust, and commitment.

It is noted that statistical power did not differ from the first approach, ranging from .706 for stress treatment on stress level to .978 for relationship investment on WoM intention. An interesting effect was found in both approaches. Stress level itself had a negative impact on relationship trust (SEM: $b=-.271$, $t(101)=2.436, p<.05$; Regression: $b=-.271, t(101)=2.334, p<.05)$. That is, despite stress having a beneficial effect on IPL, and IPL increasing trust, stress also undermined the trustworthiness of a service employee to some degree. No other substantial direct effect of stress level or stress treatment was found.

The results of the two approaches described above show ambiguous results. While the first hypotheses $(\mathrm{H} 1, \mathrm{H} 2, \mathrm{H} 3 \mathrm{a}-\mathrm{d})$ were confirmed in both approaches, there were uncertainties in hypotheses $4 \mathrm{a}-\mathrm{h}$. For this reason, Hypothesis Ha-c and $\mathrm{H} 4 \mathrm{e}-\mathrm{g}$ were rejected; only the mediation of relationship investment for both outcomes, WoM intention and repurchases intention, could be confirmed here. Table 5 summarizes the final conclusions for all hypotheses. 
Table 4 Overview of regression approach

\begin{tabular}{|c|c|c|c|c|c|c|c|}
\hline \multirow[t]{2}{*}{$\mathrm{X}$} & \multirow[t]{2}{*}{ M } & \multirow[t]{2}{*}{$\mathrm{Y}$} & \multirow{2}{*}{$\begin{array}{l}X \rightarrow M \\
b\end{array}$} & \multirow{2}{*}{$\begin{array}{l}\mathrm{M} \rightarrow \mathrm{Y} \\
\mathrm{b}\end{array}$} & \multicolumn{3}{|c|}{ Indirect effect } \\
\hline & & & & & $\mathrm{b}$ & LCI & UCI \\
\hline $\mathrm{T}$ & ST & IPL & $.318^{*}$ & $.321^{*}$ & $.102 *$ & .002 & .250 \\
\hline ST & IPL & $\mathrm{RS}$ & $.321 *$ & $.231 *$ & $.073^{*}$ & .002 & .181 \\
\hline ST & IPL & RT & $.321^{*}$ & $.238 * *$ & $.076^{*}$ & .001 & .176 \\
\hline ST & IPL & $\mathrm{RC}$ & $.321 *$ & $.407 * * *$ & $.133 *$ & .020 & .282 \\
\hline ST & IPL & RI & $.321^{*}$ & $.285^{*}$ & $.092 *$ & .006 & .218 \\
\hline IPL & $\mathrm{RS}$ & WoM & $.231 *$ & .166 & .038 & -.039 & .149 \\
\hline IPL & $\mathrm{RT}$ & WoM & $.238 * *$ & .302 & .072 & -.004 & .188 \\
\hline IPL & $\mathrm{RC}$ & WoM & $.407 * * *$ & -.109 & -.044 & -.147 & .040 \\
\hline IPL & RI & WoM & $.285^{*}$ & $.307^{*}$ & $.087 *$ & .005 & .213 \\
\hline IPL & $\mathrm{RS}$ & RP & $.231 *$ & .215 & .038 & -.039 & .149 \\
\hline IPL & RT & $\mathrm{RP}$ & $.238 * *$ & .058 & .014 & -.067 & .098 \\
\hline IPL & $\mathrm{RC}$ & $\mathrm{RP}$ & $.407 * * *$ & -.030 & -.012 & -.098 & .070 \\
\hline IPL & RI & $\mathrm{RP}$ & $.285^{*}$ & $.367 * *$ & $.104^{*}$ & .014 & .236 \\
\hline
\end{tabular}

$T$ stress treatment, $S T$ stress level, $I P L$ interpersonal liking, $R I$ relationship investment, $R S$ relationship satisfaction, $R T$ relationship trust, $R C$ relationship commitment, WoM word-of-mouth intention, $R P$ repurchase intention

$* p$ value $<.05 ; * * p$ value $<.01, * * * p$ value $<.001$

Finally, we considered gender $(0=$ male, $1=$ female $)$, student status $(0=$ nonstudent, $1=$ student $)$, and smoking $(0=$ non-smoking, $1=$ smoking $)$ as control variables in regressions to check robustness. All proposed relationships remained stable. However, smoking significantly affected relationship commitment $(b=.283, t(101)=3.113, p<.01)$ : a finding we have no plausible reasoning for, and thus deemed it as random. A Chi square test revealed that there was no significant difference between smoking and treatment group assignment $\left(\chi^{2}=.171\right.$, $p>.05$; non-smokers in no-stress group $=41$, non-smokers in stress group $=42$, smokers in no-stress group $=11$, smokers in stress group $=8$ ). Thus, we excluded having a substantially larger share of smokers or non-smokers assigned to one treatment group.

\section{Discussion}

\subsection{Findings}

Customer stress is an understudied topic in marketing and service literature. To the best of our knowledge, possible positive outcomes of stress have not been examined before in marketing research. The major finding of the present study, the positive effect of customer stress on the majority of investigated relationship outcomes such 
Table 5 Overview of hypotheses

\begin{tabular}{|c|c|c|c|c|c|}
\hline Hypothesis & $\mathrm{X}$ & Y & SEM approach & Regression approach & Conclusion \\
\hline H1 & $\mathrm{T}$ & ST & $\checkmark$ & $\boldsymbol{\nu}$ & Confirmed \\
\hline $\mathrm{H} 2$ & ST & IPL & $\checkmark$ & $\boldsymbol{\sim}$ & Confirmed \\
\hline \multicolumn{6}{|l|}{ H3 } \\
\hline $\mathrm{H} 3 \mathrm{a}$ & IPL & RS & $\checkmark$ & $\checkmark$ & Confirmed \\
\hline $\mathrm{H} 3 \mathrm{~b}$ & IPL & RT & $\checkmark$ & $\boldsymbol{v}$ & Confirmed \\
\hline $\mathrm{H} 3 \mathrm{c}$ & IPL & $\mathrm{RC}$ & $\checkmark$ & $\checkmark$ & Confirmed \\
\hline H3d & IPL & RI & $\checkmark$ & $\boldsymbol{\nu}$ & Confirmed \\
\hline \multicolumn{6}{|l|}{$\mathrm{H} 4$} \\
\hline $\mathrm{H} 4 \mathrm{a}$ & RS & WoM & $\mathrm{X}$ & $\mathrm{X}$ & Rejected \\
\hline $\mathrm{H} 4 \mathrm{~b}$ & RT & WoM & $\checkmark$ & $\mathrm{X}$ & Rejected \\
\hline $\mathrm{H} 4 \mathrm{c}$ & $\mathrm{RC}$ & WoM & $\mathrm{X}$ & $\mathrm{X}$ & Rejected \\
\hline $\mathrm{H} 4 \mathrm{~d}$ & RI & WoM & $\checkmark$ & $\checkmark$ & Confirmed \\
\hline $\mathrm{H} 4 \mathrm{e}$ & RS & $\mathrm{RP}$ & $\checkmark$ & $X$ & Rejected \\
\hline $\mathrm{H} 4 \mathrm{f}$ & RT & $\mathrm{RP}$ & $X$ & $X$ & Rejected \\
\hline $\mathrm{H} 4 \mathrm{~g}$ & $\mathrm{RC}$ & $\mathrm{RP}$ & $X$ & $X$ & Rejected \\
\hline $\mathrm{H} 4 \mathrm{~h}$ & RI & $\mathrm{RP}$ & $\boldsymbol{v}$ & $\checkmark$ & Confirmed \\
\hline
\end{tabular}

$X$ independent variable, $Y$ dependent variable, $T$ stress treatment, $S T$ stress level, $I P L$ interpersonal liking, $R I$ relationship investment, $R S$ relationship satisfaction, $R T$ relationship trust, $R C$ relationship commitment, $W o M$ word-of-mouth intention, $R P$ repurchase intention

as relationship quality and investment via increased interpersonal liking, emphasizes the role of stress in a marketing context.

\subsubsection{Theoretical contributions}

The findings provide support for the hypothesis that a higher stress level leads to a higher IPL for a service employee. Similar to the study by Dutton and Aron (1974), an increased arousal level results in increased sympathy, but in a business context. Hence, it can be supposed that customers solely attribute the arousal to which they were exposed to the employee, and thus to the company. In our view, this aspect can be explained by the theory of excitation transfer. According to Schachter's twofactor theory (1964), the increase of positive evaluations of the employee resulted from emotional arousal (stress induction) and suitable cognition (friendly employee). It is therefore encouraged to conduct further research on this theory in marketing and services. Since a customer's perception of the service employee and their interaction plays a special role in the evaluation of the service experience, a further consideration seems promising.

Furthermore, support for the assumption that IPL significantly increases perceived relationship investment was found. This can be explained by the concept that customers consider a caring and kind employee as the company's special effort in employee selection in order to show appreciation for the customer (Nicholson 
et al. 2001). This appreciation, in turn, can be interpreted as part of efforts to achieve a long-term customer relationship and can lead to increased perceived relationship investment. As expected, relationship satisfaction was found to be positively affected by interpersonal liking. A similar pattern can be found for relationship trust. Like in the personal space, people find it easier to trust employees who appear sympathetic, and vice versa. In line with Nicholson et al. (2001, p. 5), customers associate more positive motives with liked people (employees) and thus seek ways to protect and maintain the relationship. By considering trust as a twodimensional construct, in accordance with McKnight et al. (1998) as a willingness to trust the partner and the belief that this partner is trustworthy and honest (Nicholson et al. 2001, p. 4), customer willingness to invest in the relationship is strengthened by IPL. Further, according to Ahluwalia et al. (2000, p. 204), commitment is an important factor for the impact of negative emotions. Customers who are strongly committed to a company have an altered processing of information, which is contrary to their own attitudes (Ahluwalia et al. 2000). In this case, rejection or differed interpretation (according to their previous attitude) is highly likely in order to avoid negative dissonance (Festinger 1957). For example, since relationship commitment is increased, less-sensitive interactions with the same employee or company delegate have a chance to be evaluated less negatively or even to be overlooked afterward.

A support for the expectation that relationship investment enhances the intention for repurchase and WoM was found, whereas the direct effects of most relationship quality constructs on behavioral constructs revealed ambiguous results. This leads to the rejection of the majority of hypotheses $4 \mathrm{a}-\mathrm{h}$. Significant direct effects of IPL on WoM were found in both approaches. Since WoM is often directly linked with the company's online sales (e.g., Verma et al. 2016), the effect of relationship efforts on sales and revenues via positive (electronic) WoM highlights the positive potential of stress for a company's financial success (Ansary and Nik Hashim 2017). Therefore, investigating positive effects of stress more intensively is of high relevance for theory and practice. No significant direct effect of IPL on repurchase intention was found.

A surprising result is the direct effect of stress on trust. Both approaches show a positive indirect effect (mediated by IPL) but also a negative direct effect. A possible explanation might be provided by the study by Krause (1991). Krause found a positive relationship between stress and distrust. Accordingly, different stressors create distrust toward other people. Thus, a negative effect of stress is presented here, but this is more than compensated by the positive overall effect mediated by IPL. However, this also highlights the potential importance of stress intensity. It is conceivable that given an extremely high level of stress, the negative direct effect of stress on trust could endanger the positive effect on IPL. This can again emphasize the relevance of choosing a moderate stress level.

\subsubsection{Managerial implications}

Having established the positive effect of customer stress on IPL for the contact employee and relationship quality, managers should think about modifying 
instruments of customer retention in a way that possible moderate stressful or arousing situations can be used to contact new or existing customers. Applying an appropriate level, contact moments such as during traveling may be relationshipsupporting and convincing. Our results further demonstrate that the stressing situation itself does not need to be positive (e.g., rollercoaster or horror movie stressors are not required), but the interaction with the company's employee is required to be positive. If this contact is evaluated negatively (e.g., service failure), stress might impair the relationship instead of reinforcing it.

In addition, it is important that the positive influence of IPL on relationship quality and behavioral intention occurs via a customer's contact with a specific employee. According to the recommendations of Nicholson et al. (2001), it is therefore highly relevant to avoid high fluctuations of the contact staff to ensure the long-term profitability of this positive effect. As a result, managers should point out the employee's role and importance in this process as well as provide constant contact with the same employees (e.g., via matching customers with personal contacts consistently). Finally, interpersonal liking is inherently a function of attraction and attractiveness. Thus, and in line with the positive effects of stress, customer contacts should be as attractive as possible for the customer either via telephone (high speaking abilities, positively associated dialects or no dialects), written conversation, and personal interaction (dress codes, very good condition).

\subsection{Limitations and future research}

In the present study only a single contact with the employee was investigated. Therefore, it is unexplored how the relationship to the employee develops with renewed contact. Based on the present results, it seems possible that a second contact without stress or excitement may result in disappointment due to a large discrepancy between the perception of the first and second contact. Within the background of long-term customer relationships, in particular, we call for further research on this time perspective. However, in line with previous findings, interpersonal contact emphasizes the dominant importance of first sight between people on the perception of each other (Back et al. 2011).

The present study is limited to the examination of effects of stress on customer relationships. The content of a further study could be a priori, stress-promoting aspects that build on previous studies (Ruvio et al. 2014). Here, the consideration of regulatory focus theory would be interesting. Regulatory focus theory could provide insights into analyzing variations in the participant's task or the customer's concern and include possible person-specific differences in regulatory focus (Higgins et al. 1997). In the present study, it remains unknown whether the goal (to find a wellpriced and well-located hotel) is more responsive to promotion or prevention focus. Subsequent experiments with a focus on the role of regulatory focus theory with a unique distinction can investigate the assumption that stress is intensified in a prevention focus. Furthermore, according to the Yerkes-Dodson Law, a certain level of stress can lead to negative outcomes (Broadhurst 1957; Hanoch and Vitouch 2004). Consequently, very high stress levels may cause decreasing IPL for the service employee. 
This research is limited to the role of stress in a consumer marketing context; further research on business-to-business marketing could be promising. From a management perspective, knowledge spillover plays an important role in this context, especially for strategic entrepreneurship (Ferreira et al. 2017). Research on knowledge spillover examines the role of unintentional knowledge transfer between organizations (Ko and Liu 2015: 663; Ferreira et al. 2017). In contact situations, it would be conceivable that effects of stress from the present paper could lead to unintended knowledge provision as a consequence of increased interpersonal liking and thus an overestimation of the relationship, for example, if firm representatives are jointly exposed to stimulating but somewhat stressful situations like workshops or trade fairs.

Another relevant issue is controllability. According to Grégoire and Fisher (2006), the company's controllability of a service interaction (especially failure) as perceived by the customer influences the customer's evaluation and reaction. In the present study, it can be assumed that subjects do not assign the controllability of the stressor to the company, since both processes are obviously separate. A less clear separation from the customer's perspective may alter the positive effect of stress.

From a methodological point of view, the present study is limited with respect to the laboratory setting. Generally, laboratory studies are characterized by high internal but low external validity (Mitchell 2012). In the present case, it can be assumed that real stress causes comparable physical responses, as in the case of an artificial stress induction (Cheng 2001). In real stress situations, however, some factors may influence the effect of stress on employee perception (e.g., the mood of the consumer or of the employee would be conceivable). Thus, further research on potential influencing factors could provide additional insights.

Open Access This article is distributed under the terms of the Creative Commons Attribution 4.0 International License (http://creativecommons.org/licenses/by/4.0/), which permits use, duplication, adaptation, distribution and reproduction in any medium or format, as long as you give appropriate credit to the original author(s) and the source, provide a link to the Creative Commons license and indicate if changes were made.

\section{References}

Agariya AK, Singh D (2011) What really defines relationship marketing? A review of definitions and general and sector-specific defining constructs. J Relatsh Market 10(4):203-237

Ahluwalia R, Burnkrant RE, Unnava HR (2000) Consumer response to negative publicity: the moderating role of commitment. J Market Res 37(2):203-214

Albrecht CM, Hattula S, Bornemann T, Hoyer WD (2016) Customer response to interactional service experience: the role of interaction environment. J Serv Manag 27(5):704-729

Ansary A, Nik Hashim NM (2017) Brand image and equity: the mediating role of brand equity drivers and moderating effects of product type and word of mouth. Rev Manag Sci. https://doi.org/10.1007/ s11846-017-0235-2

Back MD, Schmukle SC, Egloff B (2011) A closer look at first sight: social relations lens model analysis of personality and interpersonal attraction at zero acquaintance. Eu J Personal 25(3):225-238

Backé EM, Seidler A, Latza U, Rossnagel K, Schumann B (2012) The role of psychosocial stress at work for the development of cardiovascular diseases: a systematic review. Int Arch Occup Environ Health 85(1):67-79 
Bagozzi RP, Yi Y (1989) On the use of structural equation models in experimental designs. J Market Res 26(3):271-284

Bodenmann G, Meuwly N, Bradbury TN, Gmelch S, Ledermann T (2010) Stress, anger, and verbal aggression in intimate relationships: moderating effects of individual and dyadic coping. J Soc Pers Relatsh 27(3):408-424

Boles JS, Babin BJ (1996) On the front lines: Stress, conflict, and the customer service provider. J Bus Res 37(1):41-50-2

Broadhurst PL (1957) Emotionality and the Yerkes-Dodson law. J Exp Psychol 54(5):345-352

Caballero M, Resnik AJ (1986) The attraction paradigm in dyadic exchange. Psychol Market 3(1):17-34

Cantor JR, Zillmann D, Bryant J (1975) Enhancement of experienced sexual arousal in response to erotic stimuli through misattribution of unrelated residual excitation. J Pers Soc Psychol 32(1):69-75

Chan KW, Yim CK, Lam SS (2010) Is customer participation in value creation a double-edged sword? Evidence from professional financial services across cultures. J Market 74(3):48-64

Cheng C (2001) Assessing coping flexibility in real-life and laboratory settings: a multimethod approach. J Pers Soc Psychol 80(5):814-833

Clore GL, Gormly JB (1974) Knowing, feeling, and liking a psychophysiological study of attraction. J Res Pers 8(3):218-230

Cohen S, Tyrrell DA, Smith AP (1993) Negative life events, perceived stress, negative affect, and susceptibility to the common cold. J Pers Soc Psychol 64(1):131-140

Crosby LA, Evans KR, Cowles D (1990) Relationship quality in services selling: an interpersonal influence perspective. J Market 54(3):68-81

Crum AJ, Salovey P, Achor S (2013) Rethinking stress: the role of mindsets in determining the stress response. J Pers Soc Psychol 104(4):716-733

Darden WR, DeConinck JB, Babin BJ, Griffin M (1991) The role of consumer sympathy in product liability suits: an experimental investigation of loose coupling. J Bus Res 22(1):65-89

DeWulf KD, Odekerken-Schröder G, Iacobucci D (2001) Investments in consumer relationships: a crosscountry and cross-industry exploration. J Market 65(4):33-50

Dutton DG, Aron AP (1974) Some evidence for heightened sexual attraction under conditions of high anxiety. J Pers Soc Psychol 30(4):510-517

Etkin J, Evangelidis I, Aaker J (2015) Pressed for time? Goal conflict shapes how time is perceived, spent, and valued. J Market Res 52(3):394-406

Fay D, Sonnentag S (2002) Rethinking the effects of stressors: a longitudinal study on personal initiative. J Occup Health Psychol 7(3):221-234

Ferreira JJ, Ratten V, Dana LP (2017) Knowledge spillover-based strategic entrepreneurship. Int Entrep Manag J 13(1):161-167

Festinger L (1957) A theory of cognitive dissonance. Stanford University Press, Stanford

Fornell C, Larcker DF (1981) Evaluating structural equation models with unobservable variables and measurement error. J Market Res 18(1):39-50

Foster CA, Witcher BS, Campbell WK, Green JD (1998) Arousal and attraction: evidence for automatic and controlled processes. J Pers Soc Psychol 74(1):86-101

Grégoire Y, Fisher RJ (2006) The effects of relationship quality on customer retaliation. Market Lett 17(1):31-46

Grégoire Y, Tripp TM, Legoux R (2009) When customer love turns into lasting hate: the effects of relationship strength and time on customer revenge and avoidance. J Market 73(6):18-32

Grönroos C (1990) Relationship approach to the marketing function in service contexts: the marketing and organizational behavior interface. J Bus Res 20(1):3-12

Hanoch Y, Vitouch O (2004) When less is more information, emotional arousal and the ecological reframing of the Yerkes-Dodson law. Theor Psychol 14(1):427-452

Higgins ET, Shah J, Friedman R (1997) Emotional responses to goal attainment: strength of regulatory focus as moderator. J Pers Soc Psychol 72(3):515-525

Homburg C, Giering A (2001) Personal characteristics as moderators of the relationship between customer satisfaction and loyalty-an empirical analysis. Psychol Market 18(1):43-66

Kahn BE, Baron J (1995) An exploratory study of choice rules favored for high-stakes decisions. J Consum Psychol 4(4):305-328

Kirschbaum C, Pirke KM, Hellhammer DH (1993) The 'Trier Social Stress Test' — a tool for investigating psychobiological stress responses in a laboratory setting. Neuropsychobiology 28(1-2):76-81

Ko WW, Liu G (2015) Understanding the process of knowledge spillovers: the learning to become social enterprises. Strateg Entrepreneurship J 9(3):263-285 
Kraus S, Filser M, Eggers F, Hills GE, Hultman CM (2012) The entrepreneurial marketing domain: a citation and co-citation analysis. J Res Market Entrepreneurship 14(1):6-26

Kraus S, Meier F, Niemand T (2016) Experimental methods in entrepreneurship research: the status quo. Int J Entrep Behav Res 22(6):958-983

Krause N (1991) Stress and isolation from close ties in later life. J Gerontol 46(4):183-194

Kunreuther H, Meyer R, Zeckhauser R et al (2002) High stakes decision making: normative, descriptive, and prescriptive considerations. Market Lett 13(3):259-268

Lazarus RS, Folkmann S (1984) Stress, appraisal, and coping. Springer, New York

Leischnig A, Ivens BS, Henneberg SC (2015) When stress frustrates and when it does not: configural models of frustrated versus mellow salespeople. Psychol Market 32(11):1098-1114

Maes S, Vingerhoets AJJM, Van Heck G (1987) The study of stress and disease: some developments and requirements. Soc Sci Med 25(6):567-578

Maier E, Wilken R (2014) The impact of stress on consumers' willingness to pay. Psychol Market 31(9):774-785

Mang S, Post D, Spann M (2012) Pricing of flexible products. Rev Manag Sci 6(4):361-374

Mattes J, Cantor J (1982) Enhancing responses to television advertisements via the transfer of residual arousal from prior programming. J Broadcast Electron 26(2):553-566

Maxham JG, Netemeyer RG (2002) Modeling customer perceptions of complaint handling over time: the effects of perceived justice on satisfaction and intent. J Retail 78(4):239-252

McKnight DH, Cummings LL, Chervany NL (1998) Initial trust formation in new organizational relationships. Acad Manag Rev 23(3):473-490

Mitchell G (2012) Revisiting truth or triviality: the external validity of research in the psychological laboratory. Perspect Psychol Sci 7(2):109-117

Morgan RM, Hunt SD (1994) The commitment-trust theory of relationship marketing. J Market 58(3):20-38

Morris MH, Schindehutte M, LaForge RW (2002) Entrepreneurial marketing: a construct for integrating emerging entrepreneurship and marketing perspectives. J Market Theory Pract 10(4):1-19

Moschis GP (2007) Stress and consumer behavior. J Acad Market Sci 35(3):430-444

Netemeyer RG, Maxham JG III, Pullig C (2005) Conflicts in the work-family interface: links to job stress, customer service employee performance, and customer purchase intent. J Market 69(2):130-143

Nicholson CY, Compeau LD, Sethi R (2001) The role of interpersonal liking in building trust in longterm channel relationships. J Acad Market Sci 29(1):3-15

Nixon AE, Mazzola JJ, Bauer J, Krueger JR, Spector PE (2011) Can work make you sick? A metaanalysis of the relationships between job stressors and physical symptoms. Work Stress 25(1):1-22

Palmatier RW, Dant RP, Grewal D, Evans KR (2006) Factors influencing the effectiveness of relationship marketing: a meta-analysis. J Market 70(4):136-153

Pechmann C, Shih CF (1999) Smoking scenes in movies and antismoking advertisements before movies: effects on youth. J Market 63(3):1-13

Perry SD (2001) Commercial humor enhancement of program enjoyment: gender and program appeal as mitigating factors. Mass Commun Soc 4(1):103-116

Perry SD, Jenzowsky SA, Hester JB, King CM, Yi H (1997) The influence of commercial humor on program enjoyment and evaluation. J Mass Commun 74(2):388-399

Preacher KJ, Hayes AF (2008) Asymptotic and resampling strategies for assessing and comparing indirect effects in multiple mediator models. Behav Res Methods 40(3):879-891

Ruvio A, Somer E, Rindfleisch A (2014) When bad gets worse: the amplifying effect of materialism on traumatic stress and maladaptive consumption. J Acad Market Sci 42(1):90-101

Samson A, Voyer BG (2014) Emergency purchasing situations: implications for consumer decisionmaking. J Econ Psychol 44(5):21-33

Schachter S (1964) The interaction of cognitive and physiological determinants of emotional state. Adv Exp Soc Psychol 1(1):49-80

Schachter S, Singer J (1962) Cognitive, social, and physiological determinants of emotional state. Psychol Rev 69(5):379-399

Schwabe L, Haddad L, Schachinger H (2008) HPA axis activation by a socially evaluated cold-pressor test. Psychoneuroendocrino 33(6):890-895

Singh S, Duque LC (2012) Moderating role of stress in evaluating negative services encounters with the police. J Serv Res 15(2):231-241

Slavich GM, Irwin MR (2014) From stress to inflammation and major depressive disorder: a social signal transduction theory of depression. Psychol Bull 140(3):774-815 
Sneath JZ, Lacey R, Kennett-Hensel PA (2009) Coping with a natural disaster: Losses, emotions, and impulsive and compulsive buying. Market Lett 20(1):45-60

Starcke K, Brand M (2012) Decision-making under stress: a selective review. Neurosci Biobehav Rev 36(4):1228-1248

Swan JE, Trawick IF, Silva DW (1985) How industrial salespeople gain customer trust. Ind Market Manag 14(3):203-211

Tang Y, Deng C, Moro A (2017) Firm-bank trusting relationship and discouraged borrowers. Rev Manag Sci 11(3):519-541

Tansik DA, Routhieaux R (1999) Customer stress-relaxation: the impact of music in a hospital waiting room. Int J Serv Ind Manag 10(1):68-81

Velasco M, Gómez J, Blanco M, Rodriguez I (1997) The cold pressor test: pharmacological and therapeutic aspects. Am J Ther 4(2):34-38

Verma V, Sharma D, Sheth J (2016) Does relationship marketing matter in online retailing? A metaanalytic approach. J Acad Market Sci 44(2):206-217

Wales WJ, Gupta VK, Mousa FT (2013) Empirical research on entrepreneurial orientation: an assessment and suggestions for future research. Int Small Bus J 31(4):357-383

Wegge J, Vogt J, Wecking C (2007) Customer-induced stress in call center work: a comparison of audioand videoconference. J OccupOrgan Psychol 80(4):693-712

Zeithaml VA, Parasuraman A, Berry LL (1985) Problems and strategies in services marketing. J Market 49(2):33-46

Zeithaml VA, Berry LL, Parasuraman A (1996) The behavioral consequences of service quality. J Market 60(2):31-46

Zillmann D (1971) Excitation transfer in communication-mediated aggressive behavior. J Exp Soc Psychol 7(4):419-434

Zillmann D, Katcher AH, Milavsky B (1972) Excitation transfer from physical exercise to subsequent aggressive behavior. J Exp Soc Psychol 8(3):247-259

Zillmann D, Johnson RC, Day KD (1974) Attribution of apparent arousal and proficiency of recovery from sympathetic activation affecting excitation transfer to aggressive behavior. J Exp Soc Psychol 10(6):503-515 